\title{
Design, development, calibration, and testing of indigenously developed strain gauge based dynamometer for cutting force measurement in the milling process
}

\author{
T. Mohanraj ${ }^{1}$, S. Shankar², R. Rajasekar ${ }^{3}$ and M.S. Uddin ${ }^{4}$ \\ 1 Department of Mechanical Engineering, Amrita School of Engineering, Coimbatore, Amrita Vishwa Vidyapeetham, INDIA \\ Phone: +91-9842581696 \\ ${ }^{2}$ Department of Mechatronics Engineering, School of Building and Mechanical Sciences, Kongu Engineering College, Erode, INDIA \\ ${ }^{3}$ Department of Mechanical Engineering, School of Building and Mechanical Sciences, Kongu Engineering College, Erode, INDIA \\ ${ }^{4}$ School of Engineering, University of South Australia, Mawson Lakes, SA 5095, AUSTRALIA
}

\begin{abstract}
In this work, a milling dynamometer based on strain gauge with an octagonal and square ring was designed and tested. Strain gauges were attached with the mechanical rings to detect the deformation, during the machining process. Wheatstone bridge circuit was equipped with gauges to acquire the strain as voltage owing to the deformation of mechanical rings when machining takes place. The finite element analysis (FEA) was used to identify the location of maximum deformation and stress. The direction of rings and location of gauges were decided to increase the sensitivity and decrease the cross-sensitivity. Then, the cutting force was acquired through NI $6221 \mathrm{M}$ series data acquisition (DAQ) card. The dynamometer had undergone a cycle of tests to verify its static and dynamic characteristics. The metrological characterization was performed according to the calibration procedure based on ISO 376 - 2011 standard. The cutting force was measured with both the dynamometers through milling experiments based on Taguchi's $\mathrm{L}_{9}$ orthogonal array and the results were recorded. The measured cutting force varied from $300 \mathrm{~N}$ to $550 \mathrm{~N}$. The obtained results depicted that low-cost milling dynamometer was reliable to measure the three component machining force. Overall, the square ring based dynamometer provides the better static and dynamic characteristics in terms of linearity, cross-sensitivity (4\%), uncertainty $(0.054 \%)$, and natural frequency $(362.41 \mathrm{rev} / \mathrm{s})$.
\end{abstract}

ARTICLE HISTORY

Revised:4th Nov 2019

Accepted:12 $12^{\text {th }} \operatorname{Dec} 2019$

\section{KEYWORDS}

Milling dynamometer; milling process; cutting force; octagonal ring; square ring; strain gauge; uncertainty analysis.

\section{INTRODUCTION}

The accuracy of machining, tool wear, workpiece vibration and machining efficiency aremainly affected by cutting forces [1]. The measurement of cutting force is very essential in metal cutting industries since it is a key factor to determine the tool condition as well as to improve the machine reliability [2]. Also, the cutting force has an enormous impact on heat generation; wear and dimensional accuracy of job moreover the surface roughness of the machined part $[3,4]$. The tool condition was normally monitored using vibration [5, 6], cutting force [7] and acoustic emission (AE) signals. The cutting force has a significant role in tool condition monitoring (TCMs) [8].

Normally, two methods were utilized to measure the cutting force while machining. The first one was based on piezoelectric effect and the later one was based on piezo-resistive effect. The cutting force acted on piezoelectric crystal produced the voltage proportional to the applied force. An amplifier circuit was used to amplify the voltage and then converted to force. Generally, piezoelectric sensors are sensitive to mechanical force and have a wide range of bandwidth over $50 \mathrm{kHz}$. In contrast, they are costly and require a significant concentration while used in industry [9]. Also, they exposed to noise from nearby electrical drives [10]. Considering the later method, an elastic mechanical element with strain gauge was used as a sensor for measuring the cutting force. Normally ring element was considered as a mechanical member. Strain produced by the mechanical member was proportional to the cutting force. The produced strain was measured with the aid of a simple Wheatstone bridge circuit which was easy to design and operate [10].

The essential factor in dynamometer design is a nominal negotiation between the sensitivity, accuracy, and rigidity with a broad band of frequency. The dynamometer sensitivity was expected to generate great deformation even with smaller load while the structure of the mechanical member was below the yield strength [11]. The empirical equation was obtained with the aid of FEA to depict deformation, strain, and stress in octagonal rings. FEA results were very close with the experimental results compared with thin ring theory [12]. The dynamometer was designed and developed with strain gauges to measure the cutting force [13-15].

Various researchers designed and fabricated the dynamometers with the strain gauge for measuring the cutting force during turning and milling process up to a maximum of $4500 \mathrm{~N}$ with a sensitivity of $\pm 5 \mathrm{~N}$ and a cross sensitivity error of less than $1 \%$ [16-25]. The metrological characteristic of simple square ring shaped force transducer was studied analytically and computationally [26]. According to finite element method (FEM) calculations, a modular piezoelectric 
transducer was designed for measurement of cutting force in turning with an error of less than $5.91 \%$ and the natural frequency of $1 \mathrm{kHz}$ [27]. A rotating dynamometer was developed for measuring the machining force in face milling process [28]. Recently an innovative plate dynamometer which was able to measure the force in milling, drilling application was developed and tested [29] and the experimental study proved the outstanding characteristics of the designed device and its effectiveness for studying the advanced machining applications.

An octagonal elliptical ring based milling dynamometer was designed, developed and analyzed for cutting force measurement and the proposed design had better performance and it was suitable for small to medium size industries for milling force measurement [11]. Modified ring shaped force transducer for measuring the cutting force up to $20 \mathrm{kN}$ with an uncertainty of $\pm 0.10 \%$ was designed and developed [30-32]. High performance force and torque sensor for measuring the turning force [33,34] and milling torque [35] was developed using strain gauge. A diaphragm shaped force transducer with a strain gauge was developed and tested [36]. A new approach for milling force measurement was proposed and tested based on a fiber bragg grating sensor [37]. Recently, an integrated system based on capacitive transducer [38] was designed, developed, which was able to measure the milling force and torque simultaneously using the high precision capacitive sensors [39].

Most of the literature considered only the octagonal ring based dynamometer and its structural analysis. This paper outlines a new development of square ring dynamometer for the measurement of machining force. The designed square ring dynamometer was a low-cost device and the results were compared with the conventional octagonal ring based dynamometer. The designed dynamometer is able to measure the force components and has a provision for temperature compensation. Furthermore, the designed dynamometer has an advantage of simple structure to fabricate and appropriate for industrial use. The developed dynamometer has undergone linearity, cross sensitivity, uncertainty analysis, machining test, and the outcomes were validatedto evaluate the cutting force during milling process.

\section{DESIGN AND DEVELOPMENT OF A STRAIN GAUGE BASED DYNAMOMETER}

This work analyzes the design of octagonal and modified square ring based dynamometer. The deformation, maximum stress, and model frequency values were obtained through ring theory. A computer connection was established with NI USB $6221 \mathrm{M}$ series data acquisition (DAQ) card for acquiring the cutting force signals and logged into computer for further analysis. The cutting force measurement system was given in Figure 1.

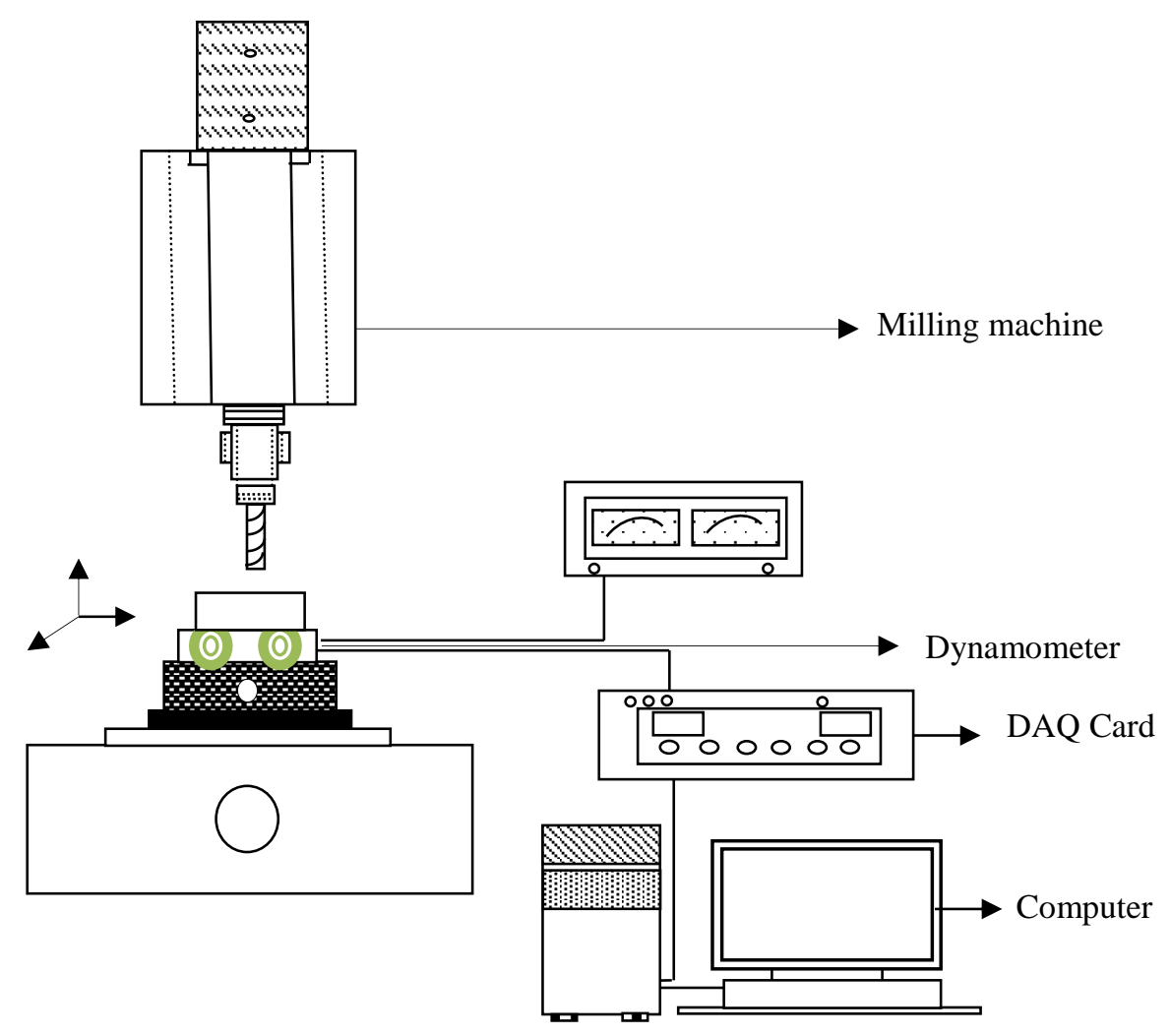

Figure 1. Simplified representation of the cutting force measurement system. 


\section{Data Acquisition}

The measurement of cutting force is an excellent approach for monitoring the tool wear [1]. For this purpose, cutting force was acquired and automatically stored in a computer. The strain signals measured from dynamometer was converted into a voltage with the aid of a Wheatstone bridge circuit. The voltage signal had very low amplitude and it was amplified using the amplifier circuit. The cable from dynamometer was connected with NI USB $6221 \mathrm{M}$ series DAQ card. The DAQ was connected with computer and LabVIEW software was used to save the signal for easy retrieval and further processing of data. The details of the equipment used for experimentation was presented in Table 1 .

Table 1. Experimental equipment and their technical properties.

\begin{tabular}{ll}
\hline Equipment & Technical properties \\
\hline Machine & L-Mill 55 \\
Dynamometer & Octagonal and square ring type strain based dynamometer \\
Strain gauge & Gauge length $=10 \mathrm{~mm} ; \mathrm{GF}=2 ;$ Gauge resistance = $350 \Omega$ \\
& Octagonal ring; material: AISI 1040 steel; \\
& $\mathrm{b}=30 \mathrm{~mm} ; \mathrm{r}=36 \mathrm{~mm} ; \mathrm{t}=10 \mathrm{~mm}$ \\
Ring element & Square ring; material: AISI 1040 steel; \\
& $\mathrm{b}=30 \mathrm{~mm} ; \mathrm{r}=30 \mathrm{~mm} ; \mathrm{t}=10 \mathrm{~mm}$ \\
Data acquisition card & USB $6221 \mathrm{M}$ series \\
Data acquisition Software & National instruments-LabVIEW \\
Power supply & $5-12 \mathrm{VDC}$ \\
\hline
\end{tabular}

\section{Design Considerations}

The necessary parameters like accuracy, sensitivity, calibration, price, and reliability have been considered for designing the milling tool dynamometer. The effective factors such as ring dimensions and material were selected by considering the dynamic characteristics of dynamometer. Fundamentally the dynamometer comprises an essential mechanical member. The stiffness and sensitivity were two opposing parameters but it is an essential requirement in dynamometer and the dynamometer has to meet the specific demands like natural frequency, extensive frequency response in addition to small cross sensitivity [20]. The ring elements were machined similar in shape and symmetrical to avoid the cross sensitivity and have a specific roughness. The stiffness, high natural frequency, resistance for corrosion and deformation under loading was considered for selecting the material. From finite element analysis, it was found that octagonal ring element was significantly rigid than circular ring and the location of maximum deformation was identified [11]. In this work, AISI 1040 steel was preferred as the material for both conventional and novel dynamometer. Table 2 shows the mechanical properties of AISI 1040 steel.

Table 2. Properties of AISI 1040 steel.

\begin{tabular}{cc}
\hline \multicolumn{2}{c}{ Mechanical Properties } \\
\hline Tensile strength & $620 \mathrm{MPa}$ \\
Young's Modulus & $210 \mathrm{Gpa}$ \\
Yield strength & $415 \mathrm{MPa}$ \\
Poisson's ratio & 0.3 \\
Hardness & $172 \mathrm{HB}$ \\
\hline
\end{tabular}

\section{Analytical Design of the Ring Elements}

The thickness ' $t$ ', radius ' $r$ ', and width ' $b$ ' of the ring are the major factors that influence the sensitivity of the dynamometer. For an octagonal ring, the ratio of sensitivity to stiffness under the application of axial load was varied as the function of thickness and radius of the ring [18]. The design principle of dynamometer was verified initially, and then fabrication of dynamometer was made based on ring theory. Considering a maximum force of $5000 \mathrm{~N}$, estimations were carried out to identify the ring dimensions. From calculations, the following dimensions were obtained and the ring was machined.

Ring width, $\mathrm{b}=30 \mathrm{~mm}$

Ring radius, $\mathrm{r}=36 \mathrm{~mm}$

Ring thickness, $\mathrm{t}=10 \mathrm{~mm}$ 
Based on estimated values, strains $\varepsilon_{r}$ and $\varepsilon_{s}$ owing to forces $F r$ as well as $F s$ were calculated using ring theory by using Eqs. (1) and (2) [13, 40].

$$
\begin{gathered}
\varepsilon_{r}= \pm \frac{1.09 F_{r} r}{E b t^{2}} \\
\varepsilon_{r}= \pm \frac{1.09 * 5000 * 36}{210000 * 30 * 10^{2}}=3.11428 \times 10^{-4} \\
\varepsilon_{s}= \pm \frac{2.18 F_{s} r}{E b t^{2}} \\
\varepsilon_{s}= \pm \frac{2.18 * 5000 * 36}{210000 * 30 * 10^{2}}=6.22857 \times 10^{-4}
\end{gathered}
$$

Stress produced on the rings due to the load was calculated by substituting $\varepsilon_{\mathrm{r}}$, $\varepsilon_{\mathrm{s}}$ values in Eqs. (3) and (4) [13, 40]:

$$
\begin{gathered}
\sigma_{r}=E \varepsilon_{r} \\
\sigma_{s}=E \varepsilon_{s}
\end{gathered}
$$

Finally, the values are calculated as, $\sigma_{\mathrm{r}}=65.39 \mathrm{Mpa}$ and $\sigma_{\mathrm{s}}=130.8 \mathrm{Mpa}$ In case of modified square ring based dynamometer, a single square ring was considered instead of four rings. For the square ring,

$$
\begin{gathered}
\text { Ring width, } \mathrm{b}=30 \mathrm{~mm} \\
\text { Ring radius, } \mathrm{r}=30 \mathrm{~mm} \\
\text { Ring thickness, } \mathrm{t}=10 \mathrm{~mm} \\
\varepsilon_{r}= \pm \frac{1.09 * 5000 * 30}{210000 * 30 * 10^{2}}=2.59523 \times 10^{-4} \\
\varepsilon_{s}= \pm \frac{2.18 * 5000 * 30}{210000 * 30 * 10^{2}}=5.1904 \times 10^{-4}
\end{gathered}
$$

$\sigma_{\mathrm{r}}=54.499 \mathrm{MPaand} \sigma_{\mathrm{s}}=108.998 \mathrm{MPa} \cdot$ For manufacturing the ring, AISI 1040 steel material was used and has the ultimate tensile strength of 620 MPaand yield strength of $415 \mathrm{GPa}$, the estimated stress values produced on the ring elements were below the safe limits for the material.

\section{Finite Element Analysis}

As another approach to analytical method, FEM was used to confirm the results of analytical method. This technique was implemented over a FEA platform (ANSYS 15). Based on the analytical model, the boundary conditions were applied over the model. The bottom flat surface was constrained in all directions and the axial force of $5000 \mathrm{~N}$ was applied on the top surface. This force value was assumed as middle range of cutting force value usually considered in small scale to medium scale machine shops. FEA was assumed to be static and linear. A 3D solid continuum sixteen node element with reduced integration was used for meshing the model. With the inputs, FEA against the structure of octagonal and modified square ring was carried out. Figure 2 shows the strain produced in octagonal ring. The strain for octagonal was $0.209 \times 10^{-}$ 7. Similarly, for modified square ring the strain was $0.245 \times 10^{-6}$. The strain for modified square ring was depicted in Figure 3. The strain values obtained from FEA was slightly higher than obtained from analytical calculation. Even though, the strain produced from modified square ring was slightly higher than octagonal ring, the structure was not affected. Figure 2 and 3 reveal the location of maximum strain occurred in the mechanical rings while apply the load. From the FE analysis the maximum strain location was identified. 

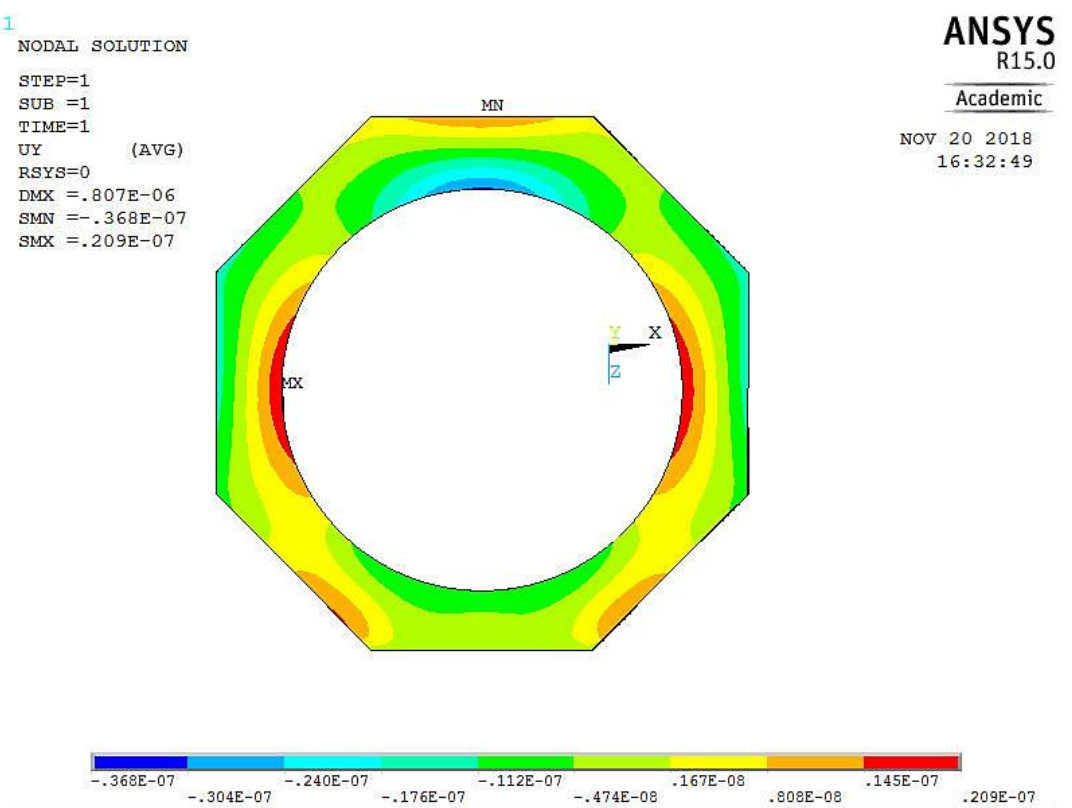

Figure 2. Strain in octagonal ring.

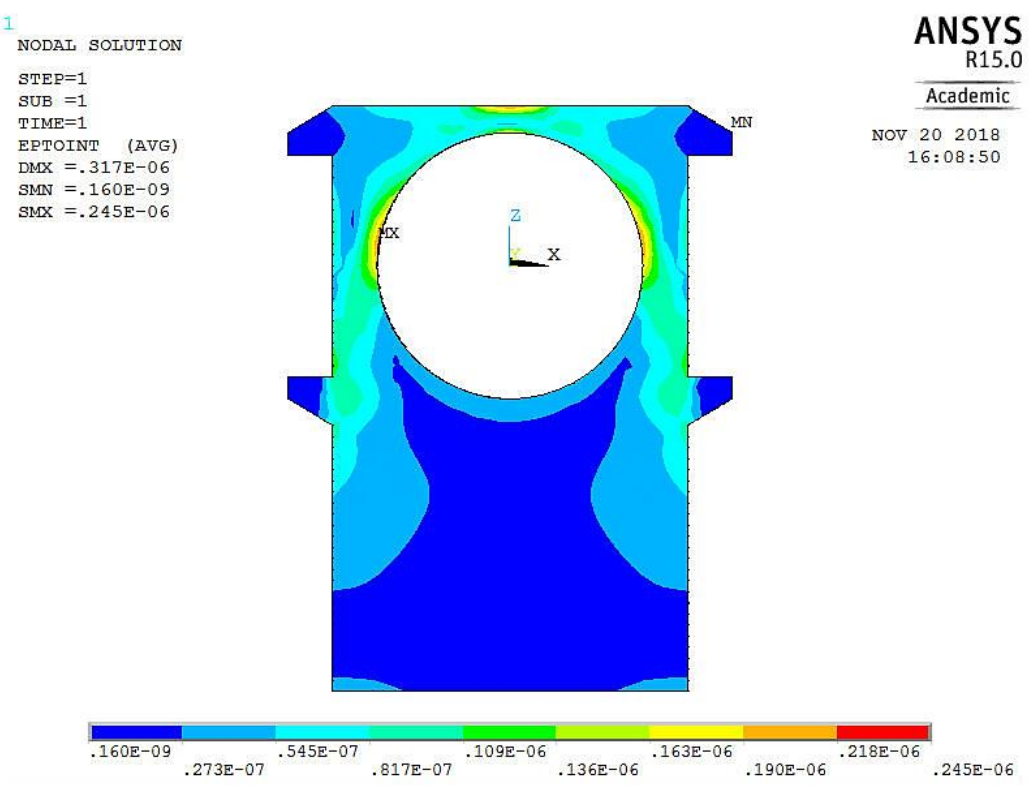

Figure 3. Strain in modified square ring.

\section{Construction of Octagonal Ring Dynamometer}

The critical component of dynamometer design was the sensing element. Four identical octagonal rings were fabricated and positioned between two plates and mounted with screws. The plates were used to increase the stiffness of rings. The cutting force was estimated during the machining process with the help of strain gauges. The fabricated octagonal ring dynamometer was presented in Figure 4. The strain gauges were attached with the ring where the maximum stress concentration occurs. Two gauges were fixed at $45^{\circ}$ on the outside of the octagonal ring element [41]. Additionally, two gauges were fixed vertically on the inner and outer side of the ring. In total, 16 gauges were fixed on the ring; each ring has four strain gauges.

Before mounting the strain gauges, the ring was coated with Zinc oxide to avoid corrosion and the ring surfaces have undergone surface preparation process to achieve better accuracy. 'M Bond 200 Catalyst' and 'M-Prep Neutralizer $5 \mathrm{~A}$ ' was used for clean the surface. Later, 'M Bond 200 Adhesive' glue was used to fix the gauges on the octagonal ring and finally the full bridge circuit was designed. The four octagonal rings were mounted between the two plates using M08 screws. The movement of ring elements due to the clearance leads to increase the cross sensitivity. This undesirable 
characteristic was reduced by maintaining uniform tightening in all screws which rigidly maintain the rings and plates. The lower plate and upper plate dimensions were $300 \times 275 \times 25 \mathrm{~mm}$.

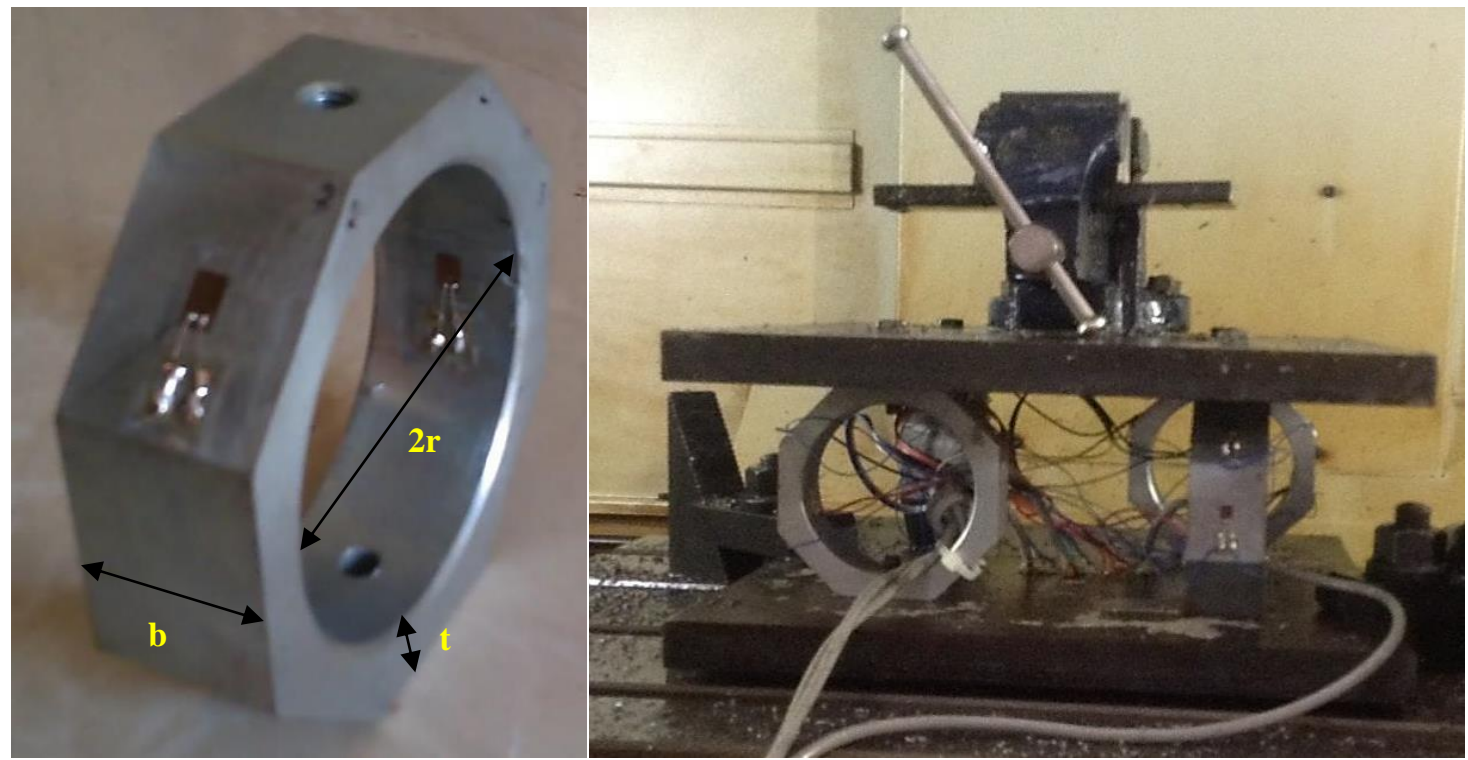

Figure 4. Fabricated octagonal ring dynamometer.

\section{Direction of the Gauges and Rings}

The appropriate choice of locations where the gauges are fixed is very much importantfor attaining the high accuracy in Wheatstone full bridge circuits. Gauge direction on the rings and location of the rings on the dynamometer was shown in Figure 5. Two considerable parameters for gauges were the resistance and gauge factor (GF). The relationship between the resistance and GF was presented in Eq. 5 [42],

$$
G F=\frac{\Delta R / R}{\Delta L / L}
$$

where,

$\Delta R$ : Changes in resistance $(\Omega)$

$R$ : Resistance of the gauge $(\Omega)$

$G F$ : Gauge factor

$\Delta L$ : Changes in gauge length $(\mathrm{mm})$

$L$ : Original length of the gauge $(\mathrm{mm})$

' $\Delta \mathrm{L} / \mathrm{L}=\varepsilon^{\prime}$. The Eq. (5) becomes ' $\mathrm{GF}=(\Delta \mathrm{R} / \mathrm{R}) / \varepsilon$ '. The voltage ratio is calculated from the given Eq. (6) [16],

$$
\begin{gathered}
\frac{U A}{U E}=\frac{1}{4}\left[\frac{\Delta R_{1}}{R_{1}}-\frac{\Delta R_{2}}{R_{2}}+\frac{\Delta R_{3}}{R_{3}}-\frac{\Delta R_{4}}{R_{4}}\right] \\
\frac{U A}{U E}=\frac{1}{4} G F\left(\varepsilon_{1}-\varepsilon_{2}+\varepsilon_{3}-\varepsilon_{4}\right)
\end{gathered}
$$

where, strain $(\varepsilon), \varepsilon_{1}=-\varepsilon_{2}=\varepsilon_{3}=-\varepsilon_{4}=\varepsilon, U A-$ Output voltage, $U E-$ Input voltage, $U A / U E=1 / 4\left(G F^{*} 4 \varepsilon\right)$ and GF $=2$, the output voltage becomes,

$$
U A=2 \varepsilon U E
$$

The output voltage was calculated from the obtained strain values based on Eq. (8). The strain values were measured from the gauges using bridge circuits. The high sensitivity and temperature compensation can be provided by using the parallel bridge circuit [41]. The strain gauges termed as S3, S4, S7, S8, S11, S12, S15, and S16 were undergone vertical force component. Among these gauges, S3, S7, S11 and S15 had tensile stresses (+) while S2, S8, S12, and S16 had compressive stresses (-). Like that the gauges S1, S2, S5, and S6 were subjected to horizontal force component; among 
these gauges S1, S5 had tensile stresses (+) while S2 and S6 had compressive stresses (-). The remaining strain gauges namely S9, S10, S13, and S14 were subjected to axial force component and S9 and S13 were subjected to the tensile stresses (+) while S10 and S14 were subjected to compressive stresses (-).

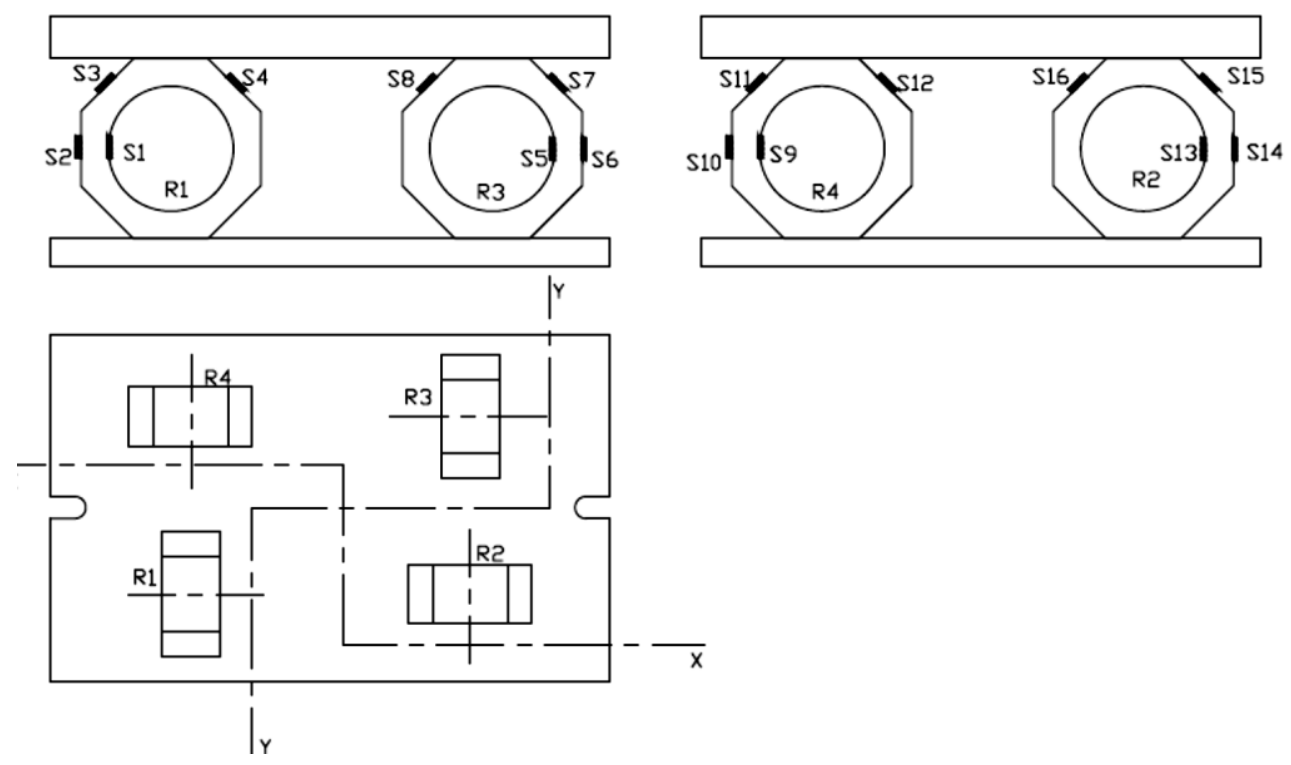

Figure 5. Position and direction of octagonal ring elements.

\section{Construction of Modified Square Ring Dynamometer}

The modified square ring based dynamometer was shown in Figure 6(a). The square ring was fabricated as per the dimensions presented in Table 1. While applying the load, maximum stress concentration was identified from the FEA simulation. The maximum strain was produced at the horizontal line of the square ring [26] which was used to sense the deformation in $Z$-axis. The square ring was fabricated along with the square bar to detect the deformation in $X$ and $Y$ axes. The $Y$-axis was aligned with machine feed direction. The same process of surface preparation was carried for modified square ring dynamometer. In total, 12 strain gauges were employed on modified square ring dynamometer. For measuring the cutting force in $\mathrm{X}$ direction, four gauges were used. These gauges were mounted on the opposite sides on the base of the ring. The other two sides were employed for Y direction. Four gauges were mounted on inner and outer surface of the square ring to measure the cutting force in $\mathrm{Z}$ direction. Two gauges were bonded on inside and outside of the ring.

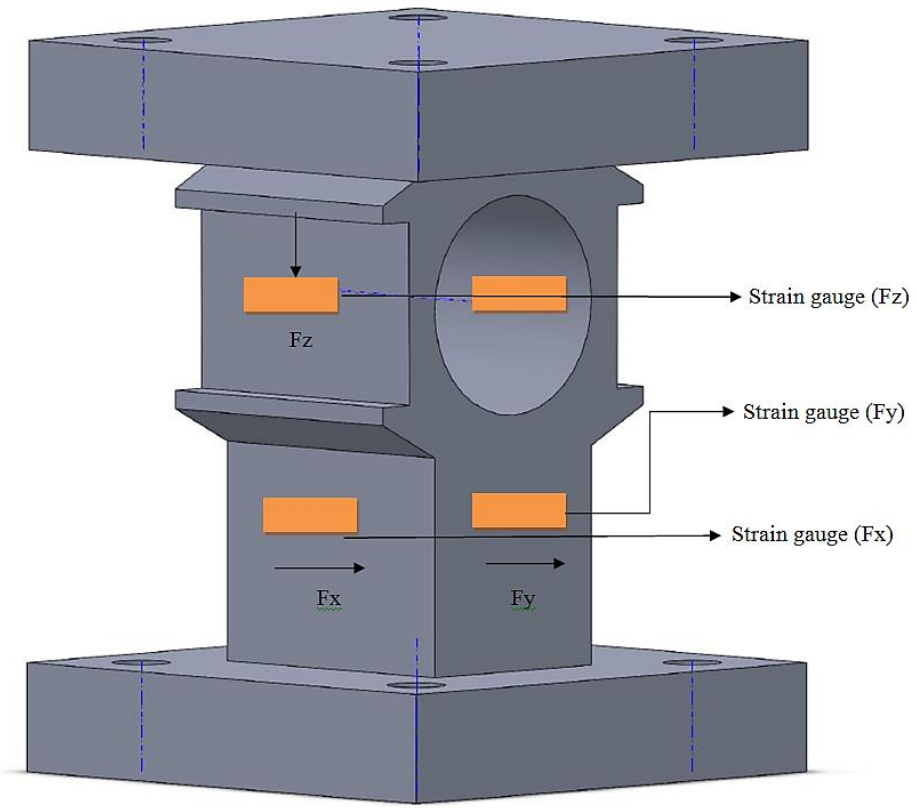

(a) 


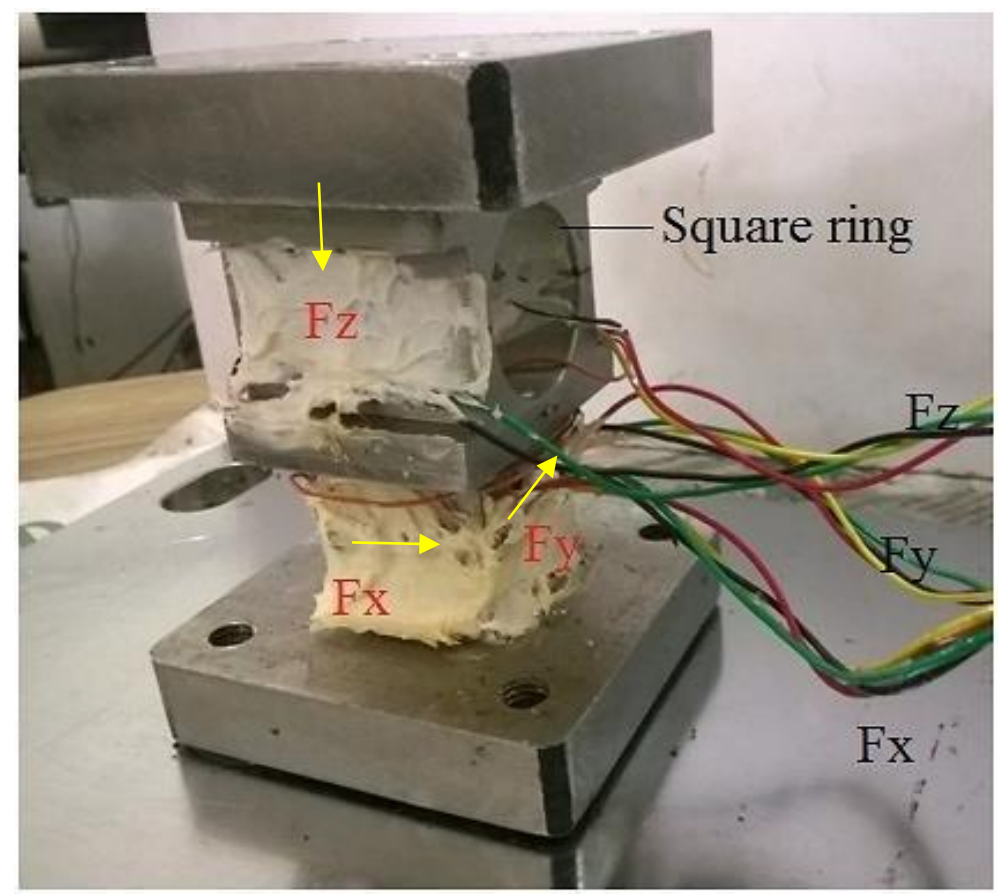

(b)

Figure 6. Modified square ring with strain gauge: (a) 3D model and (b) fabricated.

The modified square ring was fastened between the top and bottom plates using M08 screws. The ring movement was arrested and this eliminated the cross sensitivity of the dynamometer. Wheatstone bridge connections were established for the measurement of $F x, F y$ and $F z$ forces. The location of strain gauges in the modified square ring was presented in Figure 6(b). The gauges S1, S2, S3, and S4 were used to evaluate the machining force in $X$ direction. The machining force in $Y$ direction was evaluated using the gauges termed as S5, S6, S7, and S8. Similarly, the strain gauges S9, S10, S11, and $\mathrm{S} 12$ were employed to estimate the machining force in $Z$ direction. The direction marked on the dynamometer has to be physically verified while mounting the dynamometer on the machine table. The strain gauge produced the strain value, which was converted into voltage using bridge circuit. The voltage was converted into force signal.

\section{Dynamic Analysis}

The dynamometer should have a high natural frequency $\left(f_{d}\right)$ and it has to match the machine tool vibration frequency [40]. To eliminate the effect of machine tool vibrations, $f_{d}$ must be four times larger than the excited vibration frequency during the machining process [16]. Rigidity of the dynamometer depends on the natural frequency and it was given in Eq. (9).

$$
f_{d}=\frac{1}{2 \pi} \sqrt{\frac{K}{m}}
$$

where,

$\mathrm{K}$ - Ring constant of the dynamometer $(\mathrm{N} / \mathrm{mm})$,

$\mathrm{m}$ - Mass of the dynamometer $(\mathrm{kg})$,

$\mathrm{f}_{\mathrm{d}}$ - Dynamometer's Natural frequency (rev/s).

Ring constant of the dynamometer was given by the Eq. (10) [40].

$$
K_{r}=\frac{F_{r}}{\varepsilon_{r}}=\frac{E b t^{3}}{1.8 r^{3}}
$$

In this design, the dimensions of the ring and material properties were $\mathrm{t}=10 \mathrm{~mm}, \mathrm{r}=36 \mathrm{~mm}, \mathrm{~b}=30 \mathrm{~mm}$ and $\mathrm{E}=210$ GPa. The dynamometer ring constant was calculated using Eq. (10).

$$
K_{r}=\frac{F_{r}}{\varepsilon_{r}}=\frac{E b t^{3}}{1.8 r^{3}}=\frac{210000 * 30 * 10^{3}}{1.8 * 36^{3}}=75,017.146 \mathrm{~N} / \mathrm{mm}
$$


The mass of the ring was found that $31.5 \mathrm{~kg}$. Substituting the value of $\mathrm{K}$ and $\mathrm{m}$ in Eq. (9), the natural frequency was calculated $f_{d}=245.6$ rev/s. To reduce the effect of vibration due to machine tool $f_{d}>4 f_{m}$, so the spindle speed should not go beyond $3684 \mathrm{rpm}$.

For the modified square ring dynamometer, (Table 1) ring constant was calculated as follows:

$$
K_{r}=\frac{F_{r}}{\varepsilon_{r}}=\frac{E b t^{3}}{1.8 r^{3}}=\frac{210000 * 30 * 10^{3}}{1.8 * 30^{3}}=1,29,629.6296 \mathrm{~N} / \mathrm{mm}
$$

The mass of the ring was found that $25 \mathrm{~kg}$. Substituting the values of $\mathrm{K}$ and $\mathrm{m}$ in Eq. (9), the natural frequency was calculated $\mathrm{f}_{\mathrm{d}}=362.41 \mathrm{rev} / \mathrm{s}$ and the spindle speed should not go beyond $5436 \mathrm{rpm}$.

\section{RESULTS AND DISCUSSION}

\section{Dynamometer Calibration}

The designed dynamometer has to be calibrated to measure the force. The ultimate purpose is to found the elastic deformation of the ring elements and the resultant strain when subjected to different loading conditions. Static calibration was made in all the directions individually. Initially, the sensing element was placed on the milling machine for $Z$-axis calibration. A load of $50 \mathrm{~kg}$ was applied and increased gradually upto $500 \mathrm{~kg}$ for octagonal ring dynamometer and square ring dynamometer. Correspondingly, after the application of each load, the voltage from the Wheatstone bridge circuit was recorded. Subsequently, the ring was placed between the machine columns for $Y$-axis calibration and after appling each load, the voltage was measured. For $X$-axis calibration, the dynamometer was rotated by $90^{\circ}$ and the same procedure of $Y$-axis was repeated. To confirm the reliability, the test was repeated for thrice and the average output value was considered for calibration. The measured voltage was converted into a force signal. Figures 7 (a)-(c) and 8 (a)-(c) shows the calibration and cross sensitivity curves for $\mathrm{X}, \mathrm{Y}$, and $\mathrm{Z}$ axial forces, respectively for octagonal and modified square ring dynamometer. These responses obviously depict that developed dynamometer has good linearity. The octagonal and square ring based dynamometer had the linearity of $99 \%$. These calibration results were aligned with the previous literature results $[16,43]$.

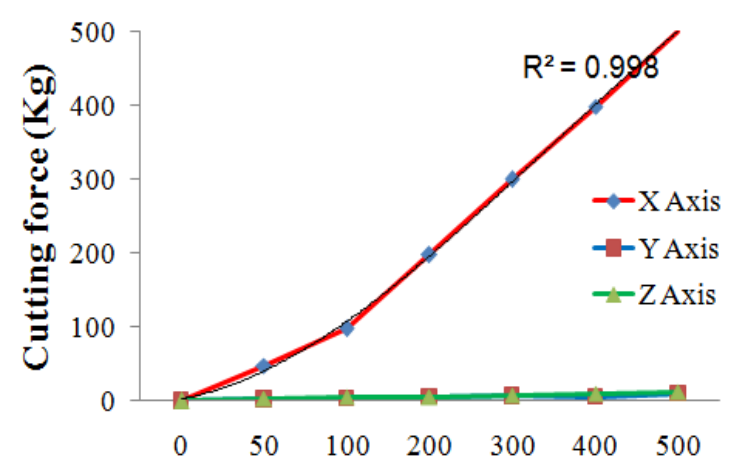

Applied load (Kg)

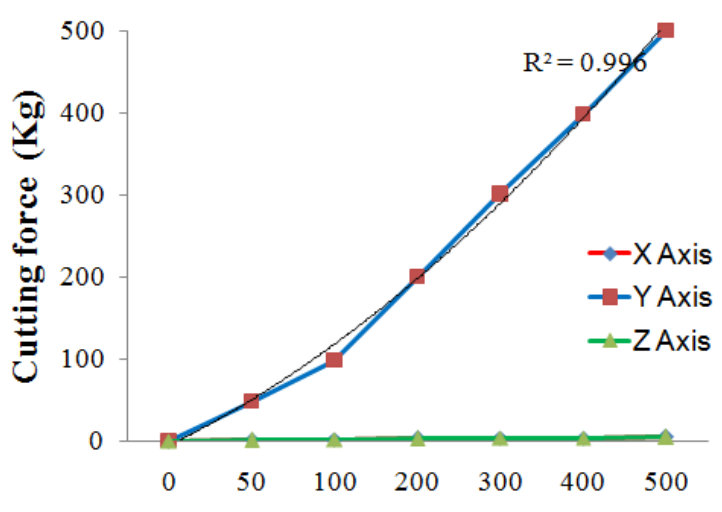

Applied Load (Kg)

(a)

(b) 


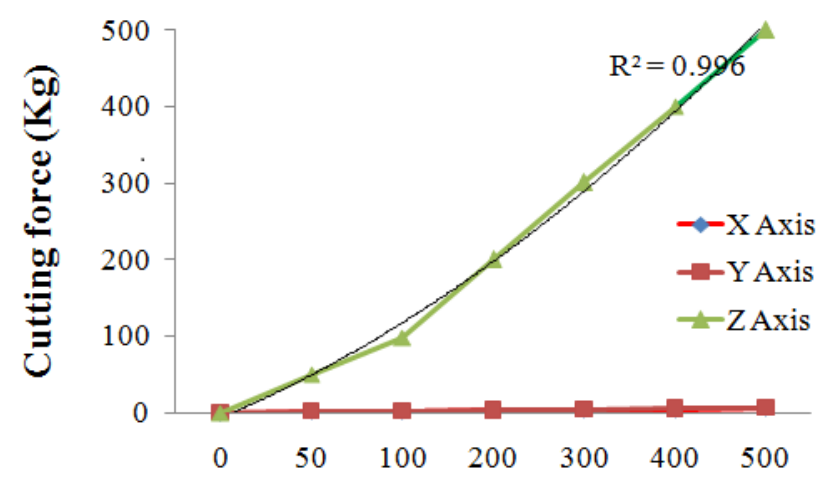

Applied Load (Kg)

(c)

Figure 7. Octagonal ring dynamometer - Calibration and cross sensitivity curve for $\mathrm{X}, \mathrm{Y}$ and Z-axis (a-c).

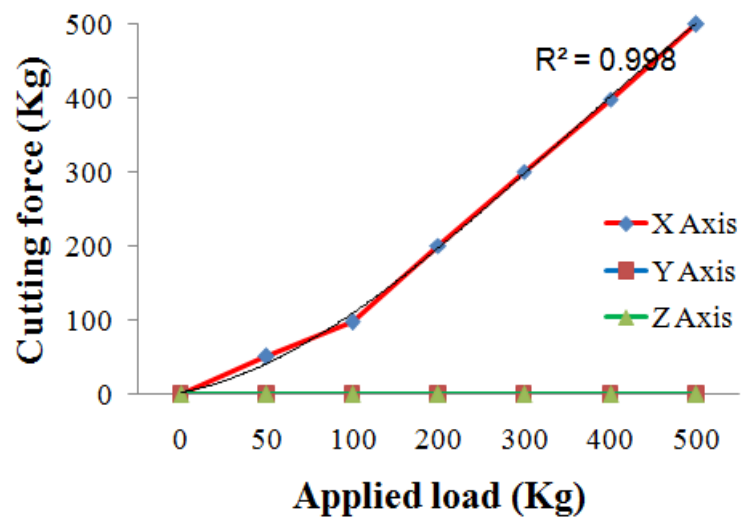

(a)

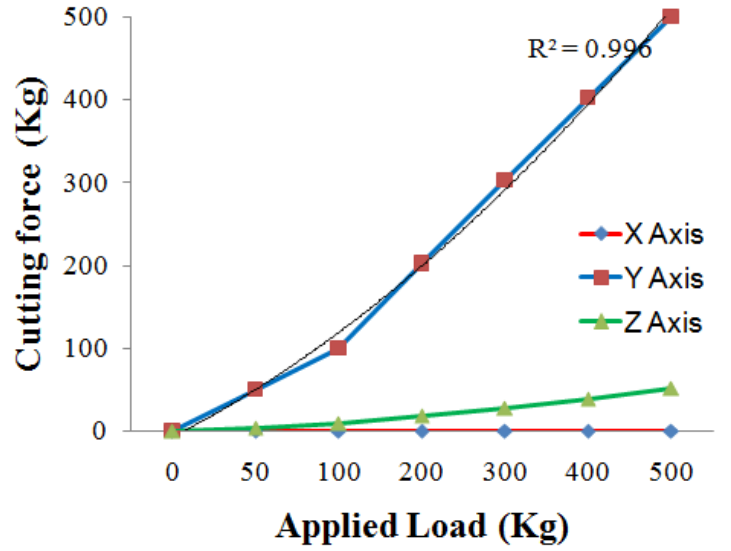

(b)

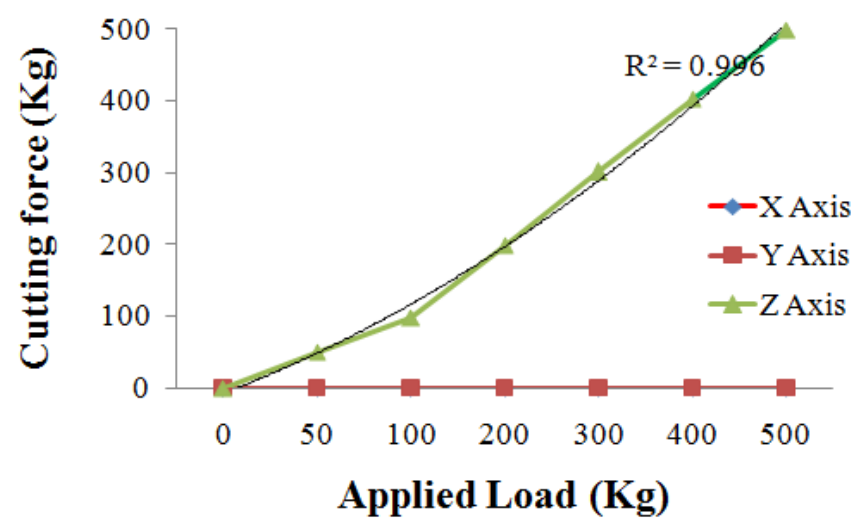

(c)

Figure 8. Modified square ring dynamometer - Calibration and cross sensitivity curve for X, Y and Z direction (a-c). 
Table 3. Cross sensitivity analysis.

\begin{tabular}{ccccccc}
\hline \multirow{2}{*}{ Load } & \multicolumn{2}{c}{ Cross Sensitivity in \% (Octagonal Ring) } & \multicolumn{2}{c}{ Cross Sensitivity in \% (Square Ring) } \\
\cline { 2 - 7 } $100 \mathrm{Kg}$ & $X$ & $Y$ & $Z$ & $X$ & $Y$ & $Z$ \\
\hline $\mathrm{X}$ & -- & 4.082 & 5.102 & -- & 0 & 0 \\
$\mathrm{Y}$ & 2.551 & -- & 2.245 & 0 & -- & 4 \\
$\mathrm{Z}$ & 3.030 & 2.828 & -- & 0 & 0 & -- \\
\hline
\end{tabular}

If the gauges were asymmetrical to the axes, then it leads to cross sensitivity error and the errors should be in the satisfactory limit. The results of cross sensitivity analysis were presented in Table 3 . The octagonal ring based dynamometer had the maximum cross sensitivity error of $6.25 \%$ in $\mathrm{Z}$-axis while load applied in the $\mathrm{X}$-axis. This may due to the misalignment of gauges on the octagonal ring. The same range of results were obtained in the previous literature [43]. In addition, the result of loading in one axis on the other axis force was also investigated and negligible variations (maximum of $4.9 \%$ ) were observed for square ring dynamometer. The square ring dynamometer had only the single ring element and had no misalignment of gauges on the ring. Hence it had very low cross sensitivity error for all the axes. The developed dynamometer had a small cross sensitivity which can be neglected. The percentage error obtained for all the cases were well below $5 \%$. The cross sensitivity was eliminated due to the single ring involved in the modified square ring dynamometer.

\section{Metrological Characterization}

The errors in measurements are unavoidable during calibration. Hence, an uncertainty analysis wascarried out for validating the measurement accuracy of designed dynamometer. Uncertainty analysis followed a calibration procedure based on ISO 376:2011 standard [26]. According to ISO 376-2011, six key uncertainty components namely repeatability, reproducibility, resolution, zero offset, hysteresis, and interpolation were considered. Combining these six individual uncertainty components, an overall uncertainty of force measurements, $W_{c}$ can be written by the Eq. (11).

$$
W_{c}=\sqrt{{W_{r p r}}^{2}+{W_{r e p}}^{2}+{W_{r e s}}^{2}+W_{z e r}^{2}+W_{h y s}^{2}+W_{\text {int }}^{2}}
$$

Eq. (11) implies, $w_{r p r}=$ relative uncertainty due to reproducibility, $w_{\text {rep }}=$ relative uncertainty due to repeatability, $w_{\text {res }}$ $=$ relative uncertainty due to resolution of strain gauge, $w_{z e r}=$ relative uncertainty due to zero offset, $w_{h y s}=$ relative uncertainty due to hysteresis, and $w_{\text {int }}=$ relative uncertainty due to interpolation. During calibration tests, loading and unloading cycles were repeated three times. The detailed mathematical expressions for estimating each uncertainty component was illustrated in [26].

Relative error due to reproducibility $\left(w_{r p r}\right)$ : For $w_{r p r}$, three calibration series in ascending order at various positions $\left(0^{\circ}, 120^{\circ}\right.$, and $\left.240^{\circ}\right)$ were considered. $w_{r p r}$ was computed from Eq. (12):

$$
w_{r p r}=\left|\frac{X_{\max }-X_{\min }}{X_{r}}\right| \times 100 \%
$$

where, $X_{\max }$ and $X_{\min }$ are the maximum and minimum values of the calibration series at a given force whilst $X_{r}$ is the reference value.

Relative error due to repeatability $\left(w_{\text {rep }}\right)$ : For $w_{\text {rep }}$, two calibration series at a given position were considered. The value of $w_{\text {rep }}$ was estimated from Eq. (13):

$$
w_{\text {rep }}=\left|\frac{X_{\text {max }}-X_{\text {min }}}{X_{w r}}\right| \times 100 \%
$$

where, $X_{w r}$ is the reference value of the given force without rotation.

Relative error due to resolution $\left(w_{\text {res }}\right)$ : The value of $w_{\text {res }}$ was estimated by dividing the resolution of the digital indicator to the mean values indicated by the digital indicator at the given resolution of force applied during calibration (Eq. (14)).

$$
w_{\text {res }}=\left[\frac{\text { Resolution }}{\text { Reference value }}\right] \times 100 \%
$$


Relative uncertainty contribution due to zero offset $\left(\mathrm{w}_{\text {zer }}\right)$ :The value of $w_{z e r}$ was calculated from the remaining values obtained after the completion of calibration series. When a transducer has undergone calibration and loaded to its nominal load (say $500 \mathrm{~kg}$ ) during calibration, after the completion of calibration and the applied load is removed, output exposed by the digital indicator is called the zero offset error. $w_{z e r}$ was estimated from Eq. (15).

$$
w_{z e r}=\left|\frac{i_{f}-i_{o}}{X_{N}}\right| \times 100 \%
$$

where, $i_{f}$ and $i_{0}$ - the maximum and minimum values of digital indicator at no load after the completion of calibration, and $\mathrm{X}_{\mathrm{N}}$ - mean value of the output of a digital indicator at full load.

Relative uncertainty contribution due to hysteresis $\left(\mathrm{w}_{\mathrm{hys}}\right)$ :It was computed as the difference of two consecutive force calibrations in ascending and descending order at a given value. This means, if a value indicated by the digital indicator at any force applied is X'in ascending order and X"in descending order of calibrations at a given force value, then the $w_{\text {hys }}$ was computed from Eq. (16):

$$
w_{\text {hys }}=\left[\frac{\left(\mathrm{X}^{\prime}-\mathrm{X}^{\prime \prime}\right)}{\mathrm{X}^{\prime}}\right] \times 100 \%
$$

Relative Error due to Interpolation ( $\mathrm{w}_{\text {int }}$ ): It was calculated based on a least square polynomial fitting method, which could be used for intermediate values (Eq. (17)).

$$
W_{\text {int }}=\frac{\bar{X}_{r}-X_{a}}{X_{a}} \times 100 \%
$$

Table 4. Uncertainty analysis of cutting force measurement using octagonal ring dynamometer with different error components.

\begin{tabular}{ccccccccc}
\hline \multirow{2}{*}{$\begin{array}{c}\text { Load } \\
(\mathrm{Kg})\end{array}$} & Repeatability & Reproducibility & $\begin{array}{c}\text { Zero } \\
\text { offset }\end{array}$ & Resolution & Hysteresis & Interpolation & $\begin{array}{c}\text { Uncertainty of } \\
\text { Measurement } \\
(\%)\end{array}$ \\
\cline { 2 - 7 } 50 & 0.08325 & 0.12285 & 0.04997 & 0.02081 & 0.020 & 0.00135 & 0.15923 \\
100 & 0.04077 & 0.06097 & 0.04997 & 0.01019 & 0.00510 & -0.01530 & 0.09078 \\
200 & 0.03027 & 0.03510 & 0.04997 & 0.00505 & 0.00505 & 0.02530 & 0.07305 \\
300 & 0.01666 & 0.00997 & 0.04997 & 0.00333 & 0.00367 & -0.03510 & 0.06427 \\
400 & 0.01000 & 0.01001 & 0.04997 & 0.00250 & 0.00498 & 0.01450 & 0.05421 \\
500 & 0.00599 & 0.00999 & 0.04997 & 0.00200 & 0 & 0.01200 & 0.05273 \\
\hline
\end{tabular}

\begin{tabular}{|c|c|c|c|c|c|c|c|}
\hline \multirow[b]{2}{*}{$\begin{array}{l}\text { Load } \\
(\mathrm{Kg})\end{array}$} & \multicolumn{6}{|c|}{ Relative error (\%) due to } & \multirow{2}{*}{$\begin{array}{c}\text { Uncertainty of } \\
\text { Measurement } \\
(\%)\end{array}$} \\
\hline & Repeatability & Reproducibility & $\begin{array}{c}\text { Zero } \\
\text { offset }\end{array}$ & Resolution & Hysteresis & Interpolation & \\
\hline 50 & 0.04940 & 0.04953 & 0.02998 & 0.01957 & 0.004 & -0.01750 & 0.08061 \\
\hline 100 & 0.05059 & 0.05051 & 0.02998 & 0.01024 & 0.00205 & -0.01540 & 0.07972 \\
\hline 200 & 0.01491 & 0.02492 & 0.02998 & 0.00499 & 0.00299 & 0.00320 & 0.04226 \\
\hline 300 & 0.01326 & 0.00995 & 0.02998 & 0.00333 & 0.001 & -0.01630 & 0.03810 \\
\hline 400 & 0.00748 & 0.00748 & 0.02998 & 0.00250 & 0.00025 & -0.02540 & 0.04077 \\
\hline 500 & 0.00400 & 0.00600 & 0.02998 & 0.00200 & 0 & 0.03520 & 0.04684 \\
\hline
\end{tabular}

Table 5. Uncertainty analysis of cutting force measurement using Modified square ring dynamometer with different error components. 
Using Eq. (11), the overall uncertainty for each measurement starting from $50 \mathrm{~kg}$ to $500 \mathrm{~kg}$ was calculated. Tables 4 and 5 summarize the uncertainty results of octagonal and modified square ring dynamometer respectively. Figure 9 compares the overall uncertainty of octagonal and modified square ring dynamometer. Uncertainty varies with load applied on the dynamometer. At smaller loads, uncertainty was larger. Conversely, as the applied load was increased, uncertainty contribution to measurement was decreased. The maximum uncertainty error of $0.15923 \%$ and $0.08061 \%$ was obtained for octagonal and modified square ring dynamometer. The designed modified dynamometer had the minimum amount of uncertainty error compared to the dynamometers designed by $[11,26]$.

\section{Uncertainity of measurement $(\%)$}

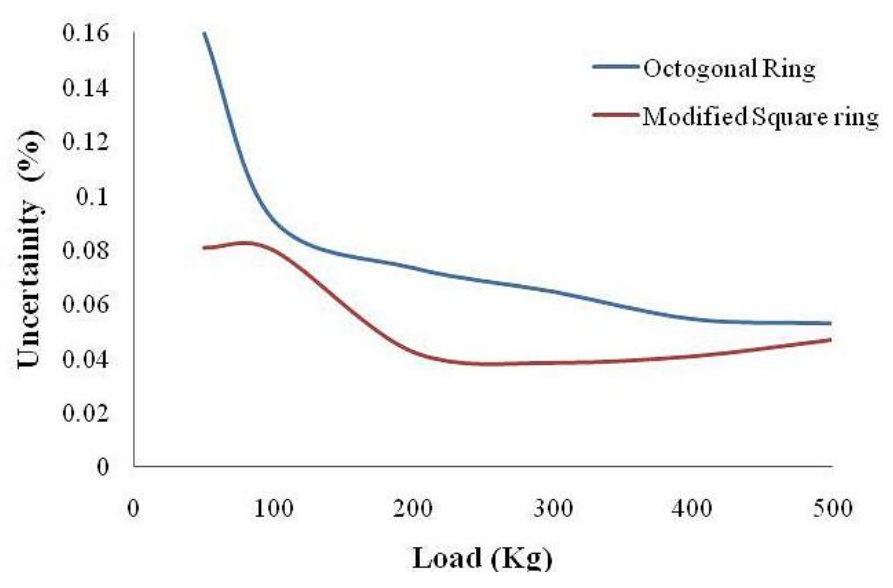

Figure 9. Overall uncertainty of measurement.

\section{Machining Test}

In order to verify the dynamic test, designed dynamometer was undergone the actual machining test in L-Mill 55 vertical machining centre. The experiments were planned and carried out with mild steel based on Taguchi's L $\mathrm{L}_{9}$ orthogonal array [44]. The experimental setup for measuring the cutting force was presented in Figure 10. During the metal cutting process, the commercial cutting fluid was used as a coolant. The measured cutting force values were recorded in Table 6. While machining process takes place, maximum of $552 \mathrm{~N}$ and $545 \mathrm{~N}$ cutting forces were measured with octagonal and square ring dynamometer. The dynamometer was designed to measure the cutting force upto $5000 \mathrm{~N}$ only. When the generated cutting force exceeds this range the sensing element may undergo plastic deformation which is not desirable.

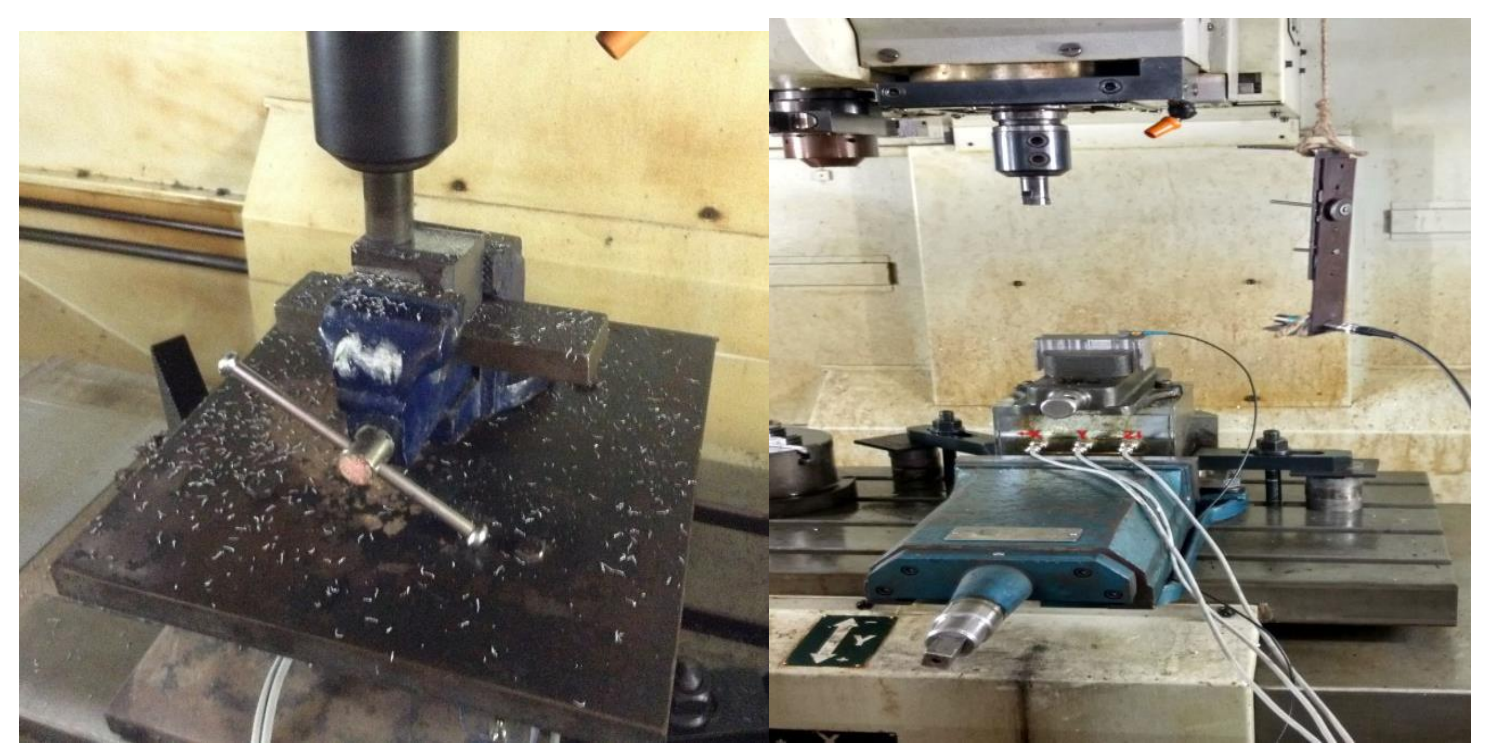

(a)

(b)

Figure 10. Machining test with (a) octagonal and (b) modified square ring dynamometer. 
Table 6. Machining test with a designed dynamometer.

\begin{tabular}{|c|c|c|c|c|c|c|c|c|c|}
\hline \multirow{2}{*}{$\begin{array}{l}\text { Exp. } \\
\text { No. }\end{array}$} & \multirow{2}{*}{$\begin{array}{l}\text { Spindle } \\
\text { speed } \\
(\mathrm{rpm})\end{array}$} & \multirow{2}{*}{$\begin{array}{l}\text { Feed rate } \\
\left(\mathrm{mm} \cdot \mathrm{rev}^{-1}\right)\end{array}$} & \multirow{2}{*}{$\begin{array}{l}\text { Depth } \\
\text { of cut } \\
(\mathrm{mm})\end{array}$} & \multicolumn{3}{|c|}{$\begin{array}{l}\text { Cutting Force }(\mathrm{N}) \text { in Octagonal } \\
\text { ring dynamometer }\end{array}$} & \multicolumn{3}{|c|}{$\begin{array}{c}\text { Cutting Force }(\mathrm{N}) \text { in Square ring } \\
\text { dynamometer }\end{array}$} \\
\hline & & & & $F x$ & $F y$ & $F z$ & $F x$ & $F y$ & $F z$ \\
\hline 1 & 600 & 0.050 & 0.5 & 140.84 & 153.70 & 178.97 & 138.50 & 150.53 & 165.84 \\
\hline 2 & 600 & 0.075 & 1.0 & 215.37 & 216.35 & 203.46 & 210.52 & 212.15 & 198.50 \\
\hline 3 & 600 & 0.100 & 1.5 & 250.88 & 223.88 & 222.11 & 250.15 & 218.69 & 215.57 \\
\hline 4 & 750 & 0.050 & 1.0 & 262.33 & 297.03 & 261.42 & 258.25 & 288.52 & 256.45 \\
\hline 5 & 750 & 0.075 & 1.5 & 280.24 & 326.28 & 289.42 & 270.52 & 312.52 & 280.12 \\
\hline 6 & 750 & 0.100 & 0.5 & 328.71 & 344.38 & 302.6 & 315.26 & 328.00 & 330.56 \\
\hline 7 & 900 & 0.050 & 1.5 & 377.12 & 360.39 & 332.42 & 365.20 & 355.54 & 360.15 \\
\hline 8 & 900 & 0.075 & 0.5 & 465.03 & 390.94 & 362.72 & 460.85 & 375.85 & 385.55 \\
\hline 9 & 900 & 0.100 & 1.0 & 552.82 & 511.98 & 508.95 & 545.65 & 505.56 & 509.82 \\
\hline
\end{tabular}

\section{CONCLUSIONS}

In this work, a strain gauge based milling dynamometer was fabricated.From calibration curves, it showed that the developed modified square ring based dynamometer had good accuracy, linearity and very less cross sensitivity (4\%) which was ignored. The metrological characterization was performed based according to the ISO 376-2011 standards. The metrological investigations of dynamometer revealed that the overall uncertainty of measurement of octagonal ring was $0.15923 \%$ and square ring dynamometer was $0.080609 \%$. The dynamometer was tested with actual machining test and it provides the better results. During the machining process, both the dynamometers measured up to $550 \mathrm{~N}$. The developed dynamometer is capable to assess a maximum of 5,000 N. So, the fabricated square ring based dynamometer was low cost, reliable and precise device with better metrological characteristics to assess the forces during machining process.

\section{ACKNOWLEDGEMENTS}

This research is supported by the AICTE - Career award for Young Teachers research grant (F No.1133/RIFD/CAYT/POL-I/2014-15). Authors are thankful to Mr. Padmanaban, Director, METCO, Coimbatore, India for his support to carry out the testing of square ring dynamometer.

\section{REFERENCES}

[1] S. Shankar and T. Mohanraj, "Tool condition monitoring in milling using sensor fusion technique," in Proceedings of Malaysian International Tribology Conference 2015, pp. 322-323.

[2] A. Nikranjbar and A. A. Atai, "Online model-based milling process condition monitoring," International Journal of Mechatronics and Manufacturing Systems, vol. 6, pp. 195-212, 2013.

[3] N. Luis, A. Lamikiz, and J. Sanchez, "Simultaneous measurement of forces and machine tool position for diagnostic of machining test," IEEE T Instrum Meas, vol. 54, pp. 2329-2335, 2005.

[4] S. Seguy, F. J. Campa, L. N. Lopez de Lacalle, L. Arnaud, G. Dessein, and G. Aramendi, "Toolpath dependent stability lobes for the milling of thin-walled parts," International Journal of Machining and Machinability of Materials, vol. 4, pp. 377-392, 2008.

[5] M. Elangovan, S. B. Devasenapati, N. R. Sakthivel, and K. I. Ramachandran, "Evaluation of expert system for condition monitoring of a single point cutting tool using principle component analysis and decision tree algorithm," Expert Systems with Applications, vol. 38, pp. 4450-4459, 2011/04/01/2011.

[6] M. Elangovan, V. Sugumaran, K. Ramachandran, and S. Ravikumar, "Effect of SVM kernel functions on classification of vibration signals of a single point cutting tool," Expert Systems with Applications, vol. 38, pp. 15202-15207, 2011.

[7] M. Tahir, J. A. Ghani, M. Z. Nuawi, M. Rizal, and C. H. C. Haron, "Flank wear and I-kaz 3D correlation in ball end milling process of Inconel 718," Journal of Mechanical Engineering and Sciences, vol. 9, pp. 1595-1603, 2015.

[8] S. Shankar, T. Mohanraj, and R. Rajasekar, "Prediction of cutting tool wear during milling process using artificial intelligence techniques," International Journal of Computer Integrated Manufacturing, vol. 32, pp. 174-182, 2019.

[9] M. Wan, H. Yuan, J. Feng, W.-H. Zhang, and W. Yin, "Industry-oriented method for measuring the cutting forces based on the deflections of tool shank," International Journal of Mechanical Sciences, vol. 130, pp. 315-323, 2017/09/01/ 2017.

[10] E. Soliman, "Performance analysis of octal rings as mechanical force transducers," Alexandria Engineering Journal, vol. 54, pp. 155-162, 2015. 
[11] M. Uddin and D. Songyi, "On the design and analysis of an octagonal-ellipse ring based cutting force measuring transducer," Measurement, vol. 90, pp. 168-177, 2016.

[12] M. Kroencke and M. Hull, "A method for designing multiload component dynamometers incorporating octagonal strain rings," Experimental Mechanics, vol. 29, pp. 195-204, 1989.

[13] S. Oraby and D. Hayhurst, "High-capacity compact three-component cutting force dynamometer," International Journal of Machine Tools and Manufacture, vol. 30, pp. 549-559, 1990.

[14] S. Shankar, S. Thangarasu, T. Mohanraj, and D. Pravien, "Prediction of cutting force in turning process: An experimental and fuzzy approach," Journal of Intelligent \& Fuzzy Systems, vol. 28, pp. 1785-1793, 2015.

[15] M. Rizal and J. A. Ghani, "Design and construction of a strain gauge-based dynamometer for a 3-axis cutting force measurement in turning process," Journal of Mechanical Engineering and Sciences, vol. 12, pp. 4072-4087, 2018.

[16] I. Korkut, "A dynamometer design and its construction for milling operation," Materials \& design, vol. 24, pp. 631-637, 2003.

[17] B. P. Pathri, A. K. Garg, D. R. Unune, H. S. Mali, S. S. Dhami, and R. Nagar, "Design and Fabrication of a Strain Gauge Type 3-axis Milling Tool Dynamometer: Fabrication and Testing," International Journal of Materials Forming and Machining Processes (IJMFMP), vol. 3, pp. 1-15, 2016.

[18] S. Yaldız, F. Ünsaçar, H. Sağlam, and H. Işık, "Design, development and testing of a four-component milling dynamometer for the measurement of cutting force and torque," Mechanical Systems and Signal Processing, vol. 21, pp. 1499-1511, 2007.

[19] A. A. Ammar, M. Jallouli, and Z. Bouaziz, "Design and development of a dynamometer for the simulation of the cutting forces in milling," International Journal of Automation and Control, vol. 5, pp. 44-60, 2010.

[20] S. Yaldız and F. Ünsaçar, "Design, development and testing of a turning dynamometer for cutting force measurement," Materials \& design, vol. 27, pp. 839-846, 2006.

[21] J. Topolnicki and N. Skoczylas, "Low cost high sensitivity dynamometer," Measurement, vol. 44, pp. 74-79, 2011/01/01/ 2011.

[22] S. Yaldız and F. Ünsaçar, "A dynamometer design for measurement the cutting forces on turning," Measurement, vol. 39, pp. 80-89, 2006/01/01/ 2006.

[23] C. Gao, W. Li, and B. Sun, "Research on the piezoelectric torsional effect of a rectangular quartz disc and a novel drilling dynamometer," Measurement, vol. 43, pp. 336-343, 2010/04/01/ 2010.

[24] R. S. Mulik, M. Mahapatra, and S. V. Gaikwad, "Design, Development, and Calibration of Octagonal Ring Type Dynamometer with FEA for Measurement of Drilling Thrust and Torque," Journal of Testing and Evaluation, vol. 48, 2018.

[25] M. I. Hanif, M. Aamir, N. Ahmed, S. Maqsood, R. Muhammad, R. Akhtar, et al., "Optimization of facing process by indigenously developed force dynamometer," The International Journal of Advanced Manufacturing Technology, vol. 100, pp. 1893-1905, February 012019.

[26] H. Kumar, C. Sharma, and A. Kumar, "The development and characterization of a square ring shaped force transducer," Measurement Science and Technology, vol. 24, p. 095007, 2013.

[27] G. Totis and M. Sortino, "Development of a modular dynamometer for triaxial cutting force measurement in turning," International Journal of Machine Tools and Manufacture, vol. 51, pp. 34-42, 2011.

[28] G. Totis, G. Wirtz, M. Sortino, D. Veselovac, E. Kuljanic, and F. Klocke, "Development of a dynamometer for measuring individual cutting edge forces in face milling," Mechanical Systems and Signal Processing, vol. 24, pp. 1844-1857, 2010.

[29] G. Totis, O. Adams, M. Sortino, D. Veselovac, and F. Klocke, "Development of an innovative plate dynamometer for advanced milling and drilling applications," Measurement, vol. 49, pp. 164-181, 2014.

[30] H. Kumar, M. Kaushik, and A. Kumar, "Development and characterization of a modified ring shaped force transducer," MAPAN, vol. 30, pp. 37-47, 2015.

[31] H. Kumar, C. Sharma, P. Arora, G. Moona, and A. Kumar, "Development and metrological characterization of a precision force transducer for static force measurement related applications," Measurement, vol. 88, pp. 77-86, 2016.

[32] H. Kumar, C. Sharma, A. Kumar, P. Arora, and S. Kumar, "Design, development and metrological characterization of a low capacity precision industrial force transducer," ISA transactions, vol. 58, pp. 659-666, 2015.

[33] Y. Zhao, Y. Zhao, S. Liang, and G. Zhou, "A High Performance Sensor for Triaxial Cutting Force Measurement in Turning," Sensors, vol. 15, pp. 7969-7984, 2015.

[34] Y. Zhao, Y. Zhao, C. Wang, S. Liang, R. Cheng, Y. Qin, et al., "Design and development of a cutting force sensor based on semi-conductive strain gauge," Sensors and Actuators A: Physical, vol. 237, pp. 119-127, 2016.

[35] Y. Qin, Y. Zhao, Y. Li, Y. Zhao, and P. Wang, "A High Performance Torque Sensor for Milling Based on a Piezoresistive MEMS Strain Gauge," Sensors, vol. 16, p. 513, 2016.

[36] R. Kumar, B. D. Pant, and S. Maji, "Development and Characterization of a Diaphragm-Shaped Force Transducer for Static Force Measurement," MAPAN, vol. 32, pp. 167-174, September 012017.

[37] M. Liu, Z. Zhang, Z. Zhou, S. Peng, and Y. Tan, "A new method based on Fiber Bragg grating sensor for the milling force measurement," Mechatronics, vol. 31, pp. 22-29, 2015.

[38] Q. Liang, D. Zhang, W. Wu, and K. Zou, "Methods and Research for Multi-Component Cutting Force Sensing Devices and Approaches in Machining," Sensors, vol. 16, p. 1926, 2016.

[39] Z. Xie, Y. Lu, and J. Li, "Development and testing of an integrated smart tool holder for four-component cutting force measurement," Mechanical Systems and Signal Processing, vol. 93, pp. 225-240, 2017.

[40] C. Milton and M. Shaw, "Metal cutting principles," ed: Clarendon Press, Oxford Science Publication, UK, 1984. 
[41] H. Saglam and A. Unuvar, "Three-component, strain gage based milling dynamometer design and manufacturing," Journal of Integrated Design and Process Science, vol. 5, pp. 95-109, 2001.

[42] S. Karabay, "Design criteria for electro-mechanical transducers and arrangement for measurement of strains due to metal cutting forces acting on dynamometers," Materials \& design, vol. 28, pp. 496-506, 2007.

[43] K. S. Murthy and I. Rajendran, "Design and development of strain gauge based milling tool dynamometer," International Journal of Machining and Machinability of Materials, vol. 7, pp. 286-298, 2010.

[44] S. Shankar, T. Mohanraj, and S. K. Thangarasu, "Multi-response milling process optimization using the Taguchi method coupled to grey relational analysis," Materials Testing, vol. 58, pp. 462-470, 2016. 